bowels, and indigestion, with all their attendant ills.

The abdominal cavity was exceedingly small, not only from approximation of its sides by squeezing the ribs, but also on account of the manner in which the lumbar vertebræ and linea alba were driven towards one another, so that the front of the lumbar portion of the spine could be plainly felt through the anterior abdominal parietes, before the body was opened.

It is not surprising that, in individuals such as this, the pregnant state should be one of great anxiety and suffering, and that œdema, or varicose condition of the veins of the lower extremities, obstinate costiveness, frequent vomiting, or weakness of the loins, should accompany it, or that recovery, after the efforts of parturition, should be lingering and tedious.

I have under my care at present a young lady, not yet 16 , where the greatest benefit was immediately experienced by throwing aside the stays, or supports for the chest, as they are called. The spine was already crooked, lateral curvature towards the left side having taken place, which has gradually given way to treatment since the stays were abandoned. The details of this case I intend to give on a future occasion.

I am, gentlemen,

Your obedient servant,

J. Nottingham,

late House Surgeon to the Liverpool

Liverpool, Oot. 27, 1841 . Infirmary.

\section{CASE OF PARALYSIS.}

By RICIIARD CHAMBERS, M.D.

Upton on Severn.

ON the 1st of May, I was requested to visit Mrs. A., æt. 45, of the sanguineo-bilious temperament. She was occasionally subject to bilious attacks, but in other respects enjoyed good health till about six weeks ago, when she was seized with vertigo, as she was about leaving her bed-room in the morning, and would have fallen, had she not caught the bed-post. 'The seizure lasted about fifteen minutes, and on recovering from it, she noticed a weakness in the right side. In a fortnight afterwards she had another seizure of a severer character. A tonic line of treatment was adopted, but to no advantage. When I saw her, she complained of headache, intolerance of light, a feeling of grittiness in the right eye, numbness of the right side of the face, paralysis of the right arm and leg, a peculiar broiling heat in the epigastrium ; pulse 96 , hard; tongue covered with a white coating; bowels confined; urine scanty; skin hot and dry; some difficulty in articulation.

'To be bled to 25 ounces; calomel and compound extr. of colocynth, of each 4 grains; James's powder, 2 grs. Two pills, to be taken at once.

Infusion of senna, 6 ounces ; sulphate of magnesia, sulphate of soda, of each 3 drachms ; tincture of senna, half an ounce. Two ounces to be taken every second hour, until the bowels are opened. A cold lotion to the head.
May 2.-Felt more comfortable after the bleeding; heat in stomach less ; bowels sparingly acted upon; pulse 96 ; in other respects the same. From the little influence produced on the pulse, although the patient complained of weakness, I was induced to examine the cardiac region, and I found the heart acting strongly. A strong impulse was communicated to the ear on the left side, as low down as the margin of the seventh rib.

Continue lotion; cupping-glasses to the neck ; nitrate of potass 2 scruples; antimonial wine and tincture of digitalis, of each 1 drachm; solution of acetate of ammonia 1 ounce; water 6 ounces. An ounce every four hours.

3. Feels better; complains less of the grittiness in the eye; pulse 88 ; nausea ; bowels confined.

Omit the mixture, repeat the cupping and other remedies.

4. Bowels freely acted upon; feels the head lighter; right side of the face very sensible of cold air; tongue coated; uneasy sensation in epigastrium; pulse 94 .

From the difficulty of getting the attendants to apply the cold lotion, I have directed the cold affusion to be substituted, and to be applied as often as the scalp feels hot.

Calomel 1 scruple; James's powder, and powdered rhubarb, of each 15 grains. Divide into 12 pills ; take one thrice a day.

Bicarbonate of soda 1 drachm; nitrate of potass 1 scruple; spirit of nitrous æther 2 drachms; almond emulsion 6 ounces. An ounce every fifth hour.

7. General symptoms unaltered; thinks she can feel the cold affusion (to use her own language) cool her stomach ; pulse 96.

Continue remedies.

10. Complains of tenderness of the gums; thirst; grittiness in the eye distressing; pulse 96 . Apply cupping-glasses to the neck; pills to be taken twice a day. Continue other remedies.

14. Mouth very sore; thinks herself better; is not sensible of any alteration in the paralysis; pulse 96.

A blister to the neck ; continue remedies.

17. Mouth still sore; general symptoms improved.

One pill only at night.

18. Does not feel so well to day, in consequence of an incautious exposure of her person during the night; feels headache and increased numbness in the face ; complains of heat in stomach ; pulse 96 ; bowels regular; tongue coated.

Take 6 ounces of blood from the neck by cupping ; continue other remedies.

19. Desires a repetition of the cupping, as it afforded so much relief; has more power in the arm and leg.

A blister to the neck.

22. Visible amendment; all symptoms better; mouth very sore; feels a desire for food; pulse 90 ; bowels confined.

Omit the pills; continue the soda and potass mixture; to have the senna mixture. Onelounce every hour until the bowels are opened. To have beef tea.

24. Is daily gathering strength; feels considerable power in the affected side.

Alkaline solution 40 drops; aromatic spirit of ammonia 1 drachm; infusion of columba 8 ounces; tincture of senna 4 drachms. An ounce thrice a 
day. To have a blister to the neck; the cold affusion thrice daily.

It is unnecessary to detail any more particulars ; from this period the convalescence of the patient, was progressive, and at the moment this is written she is in excellent health.

The foregoing case presents us with an example of disease of the brain, excited most probably by the hypertrophy of the left ventricle of the heart. The history and symptoms led us to believe that there was an effusion of blood in the first instance, and that its presence excited a degree of inflammatory action. We relied chiefly on bloodletting, mercury, and cold affusion, and the result exceeded our expectations. Had we been guided by the pulse, we would have bled more copiously, but, from the very temporary depression which the venesection produced in it, we were led to examine the state of the heart, and it was then only that we discovered what (to us) appeared to be the fountain of all the mischief.

Another circumstance claiming our attention is the state of the stomach. 'The peculiar sensation complained of existed some time before she came under our care, and was treated with effervescent salines and prussic acid, but with no amendment. We were at first inclined to think that the patient laboured under severe gastric disease, but the great relief afforded by those measures that were directed to the head affection, disclosed its real nature to be one of sympathy. Some valuable remarks on this subject have been published by Dr. Hastings of Worcester,* to which I beg to direct the attention of my readers, feeling assured that they will amply repay the trouble of perusal.

With respect to the pulse I may observe, that daily observation proves the little reliance that ought to be placed on it, as an indication of the general state of the system. About four years ago I witnessed a case of pneumonia, in which a practitioner (who was not a stethoscopist) was induced, by the strength of the pulse, to order a repetition of venesection (to $3 \times x \times x$.) for six days in succession. The patient eventually died of pulmonary apoplexy, and, on a post-mortem examination, both ventricles of the heart were found enlarged and hypertrophied. The connexion that exists between rheumatism and disease of the heart may afford us an explanation of the state of the pulse in that disease, and the injurious extent to which depletion has been carried by those who adopt it as their only guide.

November 1, 1841.

\section{PROVINCIAL}

MEDICAL \& SURGICAL JOURNAL.

SATURDAY, NOVEMBER 6,1841 .

THE treatment of persons of unsound mind in lunatic asylums has of late received a considerable share of attention, and much valuable infor.

- Midlagd Medical Reporter, No. 13. mation has been elicited, which it may be hoped will tend greatly to the amelioration of the condition of the insane. The abuses perpetrated under the methods of restraint formerly had recourse to, have been exposed, and the advantages of a milder system of management are now pretty generally admitted. The directors of many of these institutions seem willing to relax the severity of the discipline to which the patients committed to their care were subjected, and although not disposed perhaps to go to the full extent with the superintendents of the Hanwell and Lincoln Asylums, they appear to be desirous of giving a trial to measures so strongly recommended, and so much more in accordance with those feelings of benevolence by which we feel assured that they are for the most part actuated.

These considerations apply strictly to the management of those who are fitting persons to be admitted into institutions for the reception of the insane. There is, however, another branch of this subject which requires to be carefully investigated, involving, as it does, considerations of even still higher import. Notwithstanding the checks which from time to time have been placed upon the confinement of persons within the walls of lunatic establishments, and the provisions with which it has been attempted to guard against the abuse of the power necessarily entrusted to the directors, managers, and others, there is reason to fear that too great facilities are yet afforded for depriving alleged lunatics of their liberty. Persons whose state of mind, though certainly not what can be called sound, is yet scarcely such as to require confinement, are too indiscriminately sent to, and too readily immured in, these places. It is to be feared also, that the evident personal interest which the managers and officers of private asylums have in procuring patients, may often lead to abuses, difficult, if not impossible, to avoid, under the present system of admission and supervision.

We believe that most of these institutions are well conducted, and under the control of upright and conscientious individuals"; we believe also that few medical practitioners will be found to lend themselves to so atrocious an act as unnecessarily to deprive a fellow-creature of his liberty. Still neither are all members of the medical profession immaculate, nor are the proprietors and conductors of all establishments for the reception of the insane exempt from the operation of interested motives. Persons presumed to be of unsound mind have been taken by such individuals at the instance of their friends without due authority, and when the attendant practitioner has refused to certify, and certificates have been subsequently procured, by which the unfortanate 